This item was submitted to Loughborough's Research Repository by the author.

Items in Figshare are protected by copyright, with all rights reserved, unless otherwise indicated.

\title{
Predictability and underreaction in industry-level returns: Evidence from commodity markets
}

PLEASE CITE THE PUBLISHED VERSION

http://dx.doi.org/10.1016/j.jcomm.2017.02.003

PUBLISHER

(C) Elsevier

VERSION

AM (Accepted Manuscript)

\section{PUBLISHER STATEMENT}

This work is made available according to the conditions of the Creative Commons Attribution-NonCommercialNoDerivatives 4.0 International (CC BY-NC-ND 4.0) licence. Full details of this licence are available at: https://creativecommons.org/licenses/by-nc-nd/4.0/

\section{LICENCE}

CC BY-NC-ND 4.0

\section{REPOSITORY RECORD}

Valcarcel, Victor J., Andrew Vivian, and Mark Wohar. 2019. "Predictability and Underreaction in Industry-level Returns: Evidence from Commodity Markets". figshare. https://hdl.handle.net/2134/24796. 


\title{
Predictability and Underreaction in Industry-Level Returns: Evidence from Commodity Markets
}

\author{
Victor J. Valcarcel Andrew J. Vivian Mark E. Wohar
}

Original Draft: Nov. 5, 2016

THIS DRAFT: Feb. 8, 2017

\begin{abstract}
This paper finds significant evidence that commodity log price changes can predict industrylevel returns for horizons of up to six trading weeks (30 days). We find that for the 1985-2010 period, 40 out of 49 U.S. industries can be predicted by at least one commodity. Our findings are consistent with Hong and Stein's (1999) “underreaction hypothesis.” Unlike prior literature, we pinpoint the length of underreaction by employing daily data. We provide a comprehensive examination of the return linkages among 25 commodities and 49 industries. This provides a more detailed investigation of underreaction and investor inattention hypotheses than most related literature. Finally, we implement data-mining robust methods to assess the statistical significance of industry returns reactions to commodity log price changes, with precious metals (such as gold) featuring most prominently. While our results indicate modest out-of-sample forecast ability, they confirm evidence that commodity data can predict equity returns more than four trading weeks ahead.
\end{abstract}

Key Words: Asset pricing; Commodity markets; Equity markets; Industry-level returns; Information and market efficiency; Predictability; Out-of-sample forecast ability, Underreaction. JEL Classifications: G12; G14; G15; E44. 


\section{Introduction}

The "underreaction" of participants in one financial market to information originating in other segments of the financial ecosystem has been studied with theoretical and empirical frameworks. ${ }^{1}$ Hong and Stein (1999) define underreaction as a delayed reaction by equity market participants to commodity returns (log price changes). ${ }^{2}$ We examine the links between commodity and equity markets in this context. Prior literature (such as Driesprong et al., 2008, and Fan and Jahan-Parvar, 2012) generally centers on monthly energy (oil) data. We are primarily interested in how long it takes for equity markets to fully incorporate information from fluctuations in commodities.

Our approach has certain benefits compared with previous work. First, by modeling at daily frequency, we can pinpoint the length of underreaction in U.S. industry-level equity returns to information originating in commodity markets while minimizing effects of conflating dynamics at business cycle frequencies. Second, we do not limit emphasis to a single industry but undertake a comprehensive examination by considering a large swath of commodities and industries. Finally, we are one of the first papers to study gradual information diffusion among commodities and industries. We do so using an approach that explicitly accounts for datamining, which builds upon the key work of Rapach and Wohar (2006) and Herrera et al. (2011). To our knowledge, ours is the first study that documents Hong and Stein's (1999) underreaction hypothesis within the commodity markets.

The key findings of our paper are the following: First, it often takes a several weeks before commodity price information is fully incorporated into industry returns (i.e. there is an

\footnotetext{
${ }^{1}$ See Hong and Stein (1999) and Hong, Torous, and Valkanov, (2007) for examples of theoretical and empirical investigations, respectively.

${ }^{2}$ We use “(log) commodity price changes” and “commodity returns” interchangeably.
} 
underreaction), second, commodities seemingly unrelated to a sector have strong predictive ability for the returns of that particular sector, third there are strong predictive links between most commodities, considered. These findings have implications for asset allocation decisions and for market makers. For asset allocation they could assist in the timing of asset purchases or sales and suggests that information that is more two weeks old should be considered. For market makers they potentially provide information which would help them if a fall was predicted to set lower ask prices (or slightly wider spreads) to manage potential losses should a price drop occur. In addition, these results more broadly are inconsistent with the Efficient Market Hypothesis and implicitly mean that prices are not even Markovian let alone based on rational expections.

A closer look into our results indicates that we find the length of delayed reaction of US industry-level equity returns to information originating in commodity is frequently longer than 20 trading days. We determine that some non-energy commodities can predict industry equity returns. For example, since 1985 precious metals provide more evidence of equity market predictability than energy. We provide evidence using both "underreaction" methods and Granger causality tests and find that market participants react to new information with a nonnegligible lag. ${ }^{3}$ Our results indicate that information spills over slowly i) within commodity sectors and ii) from precious metals to other commodities. This gradual diffusion of information from commodity to equity markets may be surprising to proponents of the Efficient Market Hypothesis. However, this seemingly surprising observation lends support to Hong and Stein's (1999) theoretical analysis.

The rest of the paper proceeds as follows: in Section 2, we provide the background to the study. Section 3 introduces and discusses the data, while the econometric models used in this

\footnotetext{
${ }^{3}$ Studies that investigate the incorporation of macroeconomic data into equity prices such as Schwert (1981) and Pearce and Roley (1985) imply that these data are impounded into asset prices within one trading week (five trading days).
} 
study are outlined in Section 4. We present new empirical findings in Section 5. Section 6 concludes.

\section{Background}

The efficient market hypothesis implies that all relevant information is immediately incorporated into asset prices. Implicitly, this assertion means that market participants can identify relevant information and process it accurately. A growing body of literature questions this notion. Investors may focus on specific sources of information and may also be subject to behavioral biases in information processing and decision making (see, for example, Barberis and Thaler, 2003, and Hirshleifer, 2008 for a review of this literature). Few traders pay attention to all potential sources of information. Many traders specialize in very limited asset classes, certain geographic regions, certain sectors, or even trading styles. At best, they are only boundedly rational (see Shiller, 2000, and Sims, 2003). The rise of high-frequency and algorithmic trading, so far, has not fundamentally altered this fact (see Chaboud et al., 2013). Thus, time and information processing constraints may open an important avenue through which delayed reactions to commodity returns could systematically appear. Our results in this paper are consistent with this conclusion.

Hong and Stein (1999) and Hirshleifer and Teoh (2003) develop theoretical models to explain asset price behavior under conditions of limited information. ${ }^{4}$ Importantly, these theoretical models demonstrate that if there are information frictions, then asset returns can respond with a delay. Hong and Stein (1999) develop a dynamic model of a single asset in which

\footnotetext{
${ }^{4}$ Merton (1987) also develops a static model in which investors have information about a limited number of stocks and only trade those that they have information about. As a result, less recognized stocks have a smaller investor base (neglected stocks) and trade at a greater discount because of limited risk-sharing.
} 
information gradually diffuses across the investing public and investors are unable to extract information from prices. In this model, the price reacts gradually to new information (underreacts) and over time information becomes fully incorporated into stock price, leading to return predictability. Hirshleifer and Teoh (2003) suggest an alternative model where investors may not fully react to information due to limited attention and processing power. In particular, data from which it is more difficult to extract the appropriate price response is more likely to be neglected. Consequently, indirect information about an asset is less likely to be quickly incorporated into prices than direct information.

Driesprong, et al. (2008), Kilian and Park (2009), Gogineni (2010) and Fan and Jahan-Parvar (2012) examine oil prices and their impact on index and industry level returns. ${ }^{5}$ Huang et al. (1996) conjecture that information originating from a commodity market, in their case the oil futures market, may either influence the future cash flows of a company or an industry, or it may affect the discount rate. ${ }^{6}$

It is possible that commodity prices could have both a direct and an indirect impact upon industry stock returns. A direct impact could, for example, result if an industry uses the commodity as an input or produces the commodity as an output. Some commodities will only have an indirect link to industry returns. It is harder to rule out the indirect impact of any commodity's price movements on industry returns. First, commodity prices could be correlated with business cycle conditions and thus contain information that could impact expected future returns (see e.g. Fama and French, 1988). Gorton and Rouwenhorst (2006) find commodity

\footnotetext{
${ }^{5}$ Kilian and Park (2009) suggest that the response depends on whether the origin is from supply or demand shocks. They argue that the major channel is shocks to aggregate demand, rather than through aggregate supply. Lee and Ni (2002) also investigate this issue. They find that the major effects of oil price shocks are on the demand side, unless the industry is highly oil-intensive (such as industrial chemicals) where supply side dominates.

${ }^{6}$ Huang et al. (1996) use daily data, as we do in this paper, but their study is focused on the impact of price changes in crude oil futures contracts, and they do not address the underreaction question. In contrast, we are concerned with spot prices for commodities and their information content.
} 
index returns depend on phase of expansion / recession. Jacobsen, Marshall and Visaltanachoti (2010) find that the correlation between industrial metals and equity returns depends on the state of the economy. In recessions (expansions) industrial metals have a positive (negative) correlation with the business cycle. Second, a particular commodity could be correlated with other commodities that are inputs to an industry and hence could contain information about expected cash flows. Harri, Nalley and Hudson (2009) provide some evidence that corn prices and oil prices are interconnected. They conjecture that such connections could arise from corn production having become more energy-intensive as well as agricultural commodities being used to generate energy. Finally, we note that commodity prices could be a leading indicator of global economic activity. For example, Hamilton (1983) reports substantial oil price rises precede US recessions. Kilian (2009) reports that a substantial component of oil price shocks are linked to global aggregate demand.

Chng (2009) indicates there could be other connections between commodities and industry returns. He studies trading dynamics of futures contracts written on seemingly unrelated commodities but primarily used by a common industry; he finds information contained in one of these commodities is useful for predicting the other commodity futures (which are inputs to the same industry).

Extensive literature examines the speed with which asset prices respond to new information. Anderson et al. (2007) find that asset prices respond quickly to new information in their study of equity, bond and foreign exchange markets. Further support for a rapid incorporation of information—within a day is—provided by Busse and Green (2002). Nevertheless there is some evidence that markets respond with a substantial delay to some firm-specific information. Two prominent examples of this are post-earnings announcement drift (Ball and Brown, 1968) and 
price momentum (Jegadeesh and Titman, 1993). Hence, while many studies find rapid equity price responses to announcements, there are some important exceptions even when direct information is considered.

Another issue examined is how quickly new information is embedded into commodities. There is some evidence that commodity prices respond very quickly to their own production information (Milonas, 1987; Colling and Irwin, 1990). However, for oil there is some interesting evidence that questions how responsive oil prices are to potentially important announcements. Brunetti et al. (2011) report that oil prices do not respond to OPEC (production) announcements, while Kilian and Vega (2011) report oil prices do not respond to U.S. macroeconomic announcements. Nonetheless, it is possible that oil is a leading indicator of macroeconomic conditions, hence announcement information is already incorporated into the oil price. In contrast, there is evidence that agricultural commodities respond quickly to direct relevant information. For example, Milonas (1987) finds agricultural prices respond to USDA crop announcements. Colling and Irwin (1990) provide evidence for the livestock market, confirming that prices generally adjust to unanticipated changes on the day following the release of USDA information. ${ }^{7}$ Hence, the findings for oil might not necessarily hold for non-energy commodities.

\section{Data}

The data sample is January 1985 to December 2014 at a daily frequency. This covers our initial in-sample period from January 1985 to July 2010, which is subsequently extended through

\footnotetext{
${ }^{7}$ Colling and Irwin (1990) also find livestock prices do not react to anticipated changes in reported information.
} 
to December 2014 to provide for an out-of-sample forecasting period. ${ }^{8}$ The full sample period covers the early 1990s global recession, the more recent financial crisis, as well as periods of economic growth.

Industry level return data is taken from Kenneth R. French's data bank. We consider 47 industry level portfolios measured at daily frequencies. These portfolios are annually rebalanced at the end of June, and their industry classifications are based on four-digit SIC codes. ${ }^{9}$ The portfolio returns used are value-weighted across firms in the relevant industry. Commodity data is based upon daily spot price data taken from Thomson's Datastream. ${ }^{10}$ The log of the change in commodity price is used to calculate the commodity return. A broad cross-section of 25 different commodities are investigated covering diverse sectors from energy to grains, from precious metals to softs and from industrial metals to livestock.

\section{Econometric Methodology}

In this section, we describe our econometric approach for detection of predictability in commodity markets and from commodity markets to equity market at the industry level.

\subsection{Granger Causality Investigation}

We use the well-known linear Granger causality approach (Granger, 1969, and Sims, 1972). The estimated statistical model is vector autoregression (VAR) of the form:

\footnotetext{
${ }^{8}$ Goyal and Welch (2008) contend that many positive predictability results in the literature depend on the sample period containing the 1974 oil price shock. Our data is not subject to Goyal and Welch's contention because our empirical analysis begins in 1985.

${ }^{9}$ A descriptive table is available upon request. Further information on the industry level return dataset is available from Kenneth French’s website: http://mba.tuck.dartmouth.edu/pages/faculty/ken.french/data_library.html

${ }^{10}$ For more detailed description of the commodity data employed, see Vivian and Wohar (2012), especially Appendix A, who use a shorter sample of the same commodity data in their study.
} 


$$
\begin{aligned}
& r_{t}^{i}=\mu_{i}+\sum_{j=1}^{J} \phi_{i, j} r_{t-j}^{i}+\sum_{j=1}^{J} \alpha_{i, j} r_{t-j}^{c}+\varepsilon_{t}^{i} \\
& r_{t}^{c}=\mu_{c}+\sum_{j=1}^{J} \phi_{c, j} r_{t-j}^{i}+\sum_{j=1}^{J} \alpha_{c, j} r_{t-j}^{c}+\varepsilon_{t}^{c}
\end{aligned}
$$

Where $r_{t}^{i}$ and $r^{c}{ }_{t}$ are changes in industry $i$ and commodity $c$ returns. Innovations follow the usual VAR assumptions. Within the context of this VAR model, linear Granger causality restrictions are defined in the case when the null hypothesis that all $\phi_{i, j}$ are jointly equal zero is rejected. This would be the case when industry returns Granger-cause commodity log price changes. Similarly, if the null hypothesis that all $\alpha_{i, j}$ are jointly equal to zero is rejected, it is argued that lagged commodity prices Granger-cause industry returns. Different test statistics have been proposed to test for linear Granger causality restrictions. This study, similar to Huang et al. (1996), relies on the conventional $\chi^{2}$-test for joint exclusion restrictions. The Newey-West method is used to generate a robust covariance matrix.

\subsection{Predictive Regressions}

We test the underreaction hypothesis by using a variant of the predictive models used in Hong et al. (2007), Driesprong et al. (2008), and Fan and Jahan-Parvar (2012), among others. The predictive model is represented as

$$
r_{t}^{i}=\mu_{i, j}+\alpha_{i, j} r_{t-j}^{c}+\varepsilon_{t}^{i}
$$

where $r_{t}^{i}$ is industry $i$ 's returns, $\mu_{i, j}$ and $\alpha_{i, j}$ are real-valued parameters, $r_{t-j}^{c}$ represent $j^{\text {th }}$-lagged percentage change in commodity $c$ 's spot prices, and $\varepsilon_{t}^{i}$ is the error term. In contrast to most closely related literature, we estimate this model using higher frequency daily data. This predictive regression includes only one independent variable in the right hand side. The logic for this choice is to measure the longest lag that independently records any evidence of 
predictability, since we are interested in measuring the first instance of information reaching an industry from a particular commodity market.

\subsection{Robust Critical Values}

An important issue with predictive regressions is that, where the same data set is used repeatedly for inference, there is a reasonable concern about data mining. Rapach and Wohar (2006) and Herrera et al. (2011) propose remedies for this concern, which we modify for our framework and research questions. ${ }^{11}$ Consequently, the approach we implement for testing underreaction is not based on conventional critical values for the $t$-statistic. Instead, we compute empirical critical values via a bootstrap procedure in the spirit of Rapach and Wohar (2006). In this section, we explain the procedure to derive these critical values.

For each industry-commodity combination (49 industries $\times 25$ commodities), we fit equation 4.2 recursively to 1,000 non-parametric bootstrapped samples under the null of no predictability. For each bootstrapped sample, we save the $t$-statistics with the largest absolute value amongst the 30 lags (trading days), for each industry-commodity pair. Then we form the distribution of maximal absolute $t$-statistics for each commodity-industry pair combination from the 1,000 bootstrap samples and take the maximal critical value for that commodity-industry pair. In the spirit of Herrera et al. (2011) we then pool these critical values across all the regression combinations considered, which are in total 1,225 industry-commodity pairs. Specifically, we pool all the maximal critical values (from absolute $t$-statistics) across commodity-industry pairs and then we take the $10^{\text {th }}$ percentile of all these critical values as the data-mining robust $t$ statistic. These empirical critical values are much larger in absolute value than conventional

\footnotetext{
${ }^{11}$ We thank Lutz Kilian for pointing us in this direction, and Ana Maria Herrera and Walt Enders for detailed discussions leading to this solution. A detailed appendix on the bootstrap procedure can be made available upon request.
} 
critical values and, thus, subject our results to substantially more stringent criteria for statistical significance.

Because of our choice of recording the maximal absolute values of test statistics, these values are bounded away from conventional Student- $t$ values; this translates into substantially larger absolute critical values of 3.5136 at the $10 \%$ confidence level for the full sample. We pursue such stringent process to mitigate any data-mining concerns that may arise from our comprehensive investigation of industry-commodity pairs. Note that we repeat the procedure described above for each in-sample period. In turn, these high critical values will translate into substantially fewer rejections of the null hypothesis of no predictability in estimated results for equation 4.2. Thus, in empirical results, we report at most 147 -statistics from 36,750 estimated t-statistics, less than $0.5 \%$ of the total. ${ }^{12}$

\subsection{Out-of-sample forecasts}

We now outline the out-of-sample tests used in this paper. The basis of these regression results is a fixed length, sliding window regression with window size equal to 1,220 observations, or roughly five trading years. ${ }^{13}$ The out-of-sample results are based on augmenting our initial data set with observations going through to December 31, 2014, period. This adds more than four years of additional trading observations.

\footnotetext{
${ }^{12} 36,750$ estimated $t$-statistics using the actual data sample are computed since for each of the 49 industries and each of the 25 commodities, we estimate equation (4.2) with 30 commodity lags. Thus, $49 \times 25 \times 30$ gives the total number of computed $t$-statistics.

${ }^{13}$ Our results are robust to the choice of sliding window size. Based on our experimentation, reducing the window size to just 500 observations renders negligible impact on estimated values.
} 
We denote the in-sample portion of our data as $N$ and our out-of-sample portion as $M$. Thus, for a sample size equal to $T$, we have $T=N+M$. We denote the number of steps ahead in our regressions by $m$. The forecast model is

$$
r_{t+m}^{i}=\mu_{i, j}+\sum_{j=1}^{s} \alpha_{i, j} r_{t-j}^{c}+\varepsilon_{t+m}^{i} .
$$

In this exercise, $N$ corresponds to the observation number on 12/31/2010 and S corresponds to the maximal lag length found to be significant. We fit the data to equation (4.3), starting on August 1, 2010, rolling the estimating regression forward one day at a time and saving the estimation results. We then form forecasts of realized industry level returns by computing:

$$
f_{t+m}^{i}=\hat{\mu}_{i, j}+\sum_{j=1}^{s} \hat{\alpha}_{i, j} r_{t+1-j}^{c}
$$

where $m$ denotes the number of steps ahead, and estimated intercept and slope parameters - $\hat{\mu}$ and $\hat{\alpha}$ - are based on fitting equation (4.3) to the in-window returns through running an OLS regression of $m$-step ahead industry returns on commodity log price changes. The alternative model is simply the historical mean, as in Goyal and Welch (2008), where:

$$
r_{t+m}^{i}=\mu_{i}+\varepsilon_{t+m}^{i}
$$

Thus, returns forecast is simply:

$$
\tilde{f}_{t+m}^{i}=\tilde{\hat{\mu}}_{i}
$$

We then compute the forecast errors $e_{1, t+m}=r_{t+m}^{i}-f_{t+m}^{i}$ and $e_{2, t+m}=r_{t+m}^{i}-\tilde{f}_{t+m}^{i}$, respectively. Based on these two forecast error measures, we carry out forecast performance measures. 
Our main concern is whether the evidence of in-sample predictability translates into out-ofsample forecast ability. As Inoue and Kilian (2005) point out, while in-sample predictability is a necessary condition for out-of-sample forecast ability, it is not sufficient. Hence, we carry out a standard battery of forecast comparison tests to measure the ability of commodity log price changes in forecasting industry returns. To that end, we use two measures of forecast adequacy: The Clark and West (2007) test of predictive adequacy and an adjusted Theil (1971) "U measure.”

The Clark and West (2007) test statistic is specifically designed to address forecast accuracy for nested linear models, such as ours. The Clark and West (2007) test explicitly adjusts for the fact that the unrestricted model in finite samples will be subject to larger parameter estimation errors. Their test statistic, which they call the MSPE-adjusted statistic, is constructed by defining:

$$
g_{t+m}^{i}=\left(r_{t+m}^{i}-f_{t+m}^{i}\right)^{2}-\left[\left(r_{t+m}^{i}-\tilde{f}_{t+m}^{i}\right)^{2}-\left(f_{t+m}^{i}-\tilde{f}_{t+m}^{i}\right)^{2}\right] .
$$

Then by regressing $\mathrm{g}_{\mathrm{t}+\mathrm{m}}$ onto a constant and then computing the $t$-statistics corresponding to that constant, we can calculate a $p$-value for a one-sided test (upper tail) under standard Normal distribution law.

We also report Theil's (1971) adjusted U measure, where the unrestricted model forecast is adjusted for parameter estimation error as suggested by Clark and West (2007). ${ }^{14}$ This is calculated as:

$$
A d j \_U^{i}=\sqrt{\frac{\sum_{N}^{T-m}\left\{\left[\left(r_{t+m}^{i}-f_{t+m}^{i}\right)^{2}-\left[\left(r_{t+m}^{i}-\tilde{f}_{t+m}^{i}\right)^{2}-\left(f_{t+m}-\tilde{f}_{t+m}^{i}\right)^{2}\right]\right\}\right.}{\sum_{N}^{T-m}\left(r_{t+m}^{i}-\tilde{f}_{t+m}^{i}\right)^{2}}}
$$

\footnotetext{
${ }^{14}$ An adjusted out of sample $R^{2}$ is simply computed as: OOS $R^{2}=1-A d j \_U^{2}$
} 


\section{Empirical Findings}

\subsection{Granger Causality Test Results}

We find that almost every industry return is Granger-caused by multiple commodity returns. ${ }^{15}$ The lag lengths range from one to 30 days. However, the vast majority of these are in excess of five trading days and it is common to find lag lengths in excess of 20 trading days (four trading weeks).

We find the return of chemical firms is Granger caused by twenty of the twenty-five commodity returns at the $10 \%$ significance level. Interestingly, the three commodities with the shortest lead time for chemical industry returns are in the energy sector. This seems consistent with the investor inattention hypothesis. Given that chemical industry is highly energy intensive, investors should be aware of the importance of energy prices and react more quickly to these than other commodities with more opaque links. ${ }^{16}$

Figure 1 shows the lag length in the Granger causality tests for each of the 47 industries where any predictability was found from four commodities, propane, oats, nickel and gold base. These four commodities were chosen since they had the most evidence of predictability in their commodity sector (energy, grains, industrial metals and precious metals). Each of these commodities demonstrate predictability for a large majority of the equity industry returns. However, it is interesting and perhaps surprising that for most cases, significant lag lengths

\footnotetext{
${ }^{15}$ Only 47 (out of 49) industries was the null hypothesis of no Granger causality rejected at $10 \%$ confidence level or smaller by at least one commodity. Only two industries, agriculture and food, out of forty-nine industries are not Granger-caused by any commodity. It may seem surprising that there is no predictive power for agriculture or food from the grain commodities. However, this result is in line with Fan and Jahan-Parvar (2012) who find oil only has predictive ability for industries where there is no direct connection, which is consistent with investor inattention theory (Hirschleifer and Teoh, 2003). A full table of these results is available upon request.

${ }^{16}$ The chemical sector more broadly accounts for about $25 \%$ of energy consumption of all U.S. manufacturers: http://www.eia.gov/emeu/mecs/iab98/chemicals/energy_use.html
} 
exceed 20 trading days, especially for propane and gold base. This highlights again the extent of the delayed reaction of industry returns to commodity returns.

A gradual reaction of industry returns over several trading weeks is consistent with results of prior studies for oil (one key commodity) that documented underreaction using monthly data (Driesprong et al., 2008; Fan and Jahan-Parvar, 2012). Our new evidence indicates that this delayed reaction of stock returns is not confined just to oil or energy commodities but is widely apparent across a range of different commodities including precious metals and grains.

One possible reason why industry returns are predicted by so many different commodities is that commodities themselves may be inter-related. That is, commodities may predict the return of other commodities. As a robustness check, we estimated equation (4.1) replacing industry return in $r_{t}^{i}$, with another commodity return. ${ }^{17}$ We reject the null of no Granger causality for the majority of commodity pairs. This suggests that even within the commodity market, past commodity data potentially contains important information about the future returns of other commodities. $^{18}$

\subsection{Underreaction}

We fit equation 4.2 to our sampled data. ${ }^{19}$ Our goal is to provide evidence on the speed at which commodity information is incorporated into stock market returns. By using daily data, we are able to provide estimates of the number of days before current commodity information has no

\footnotetext{
${ }^{17}$ Results are available upon request.

${ }^{18}$ This mechanism is suggestive of an indirect effect. Suppose that commodity A Granger causes commodity B. Further suppose that commodity A has no clear relation to an industry, while commodity B has first or second order connections with the industry in question. Then, commodity A, through its predictive power for commodity B, can also predict the industry's costs and, by extension, its returns.

${ }^{19}$ We fit the data using individual lagged values of commodity prices, starting with $j=1$ and continuing up to $j=30$ (more than one trading month). We then record the largest such lagged commodity value where the estimated slope coefficient of our regression model is statistically different from zero. This lag-length indicates the first statistically significant spillover of information from the chosen commodity market to industry level returns in question.
} 
predictive content for future equity prices. Prior literature examining news generally finds such information is incorporated into stock returns in about a week or less (Schwert, 1981), with the bulk of evidence in favor of incorporation of data into prices in about one trading day (see, for example, Andersen et al., 2007, and Busse and Green, 2002). Driesprong et al. (2008) and Fan and Jahan-Parvar (2012) report underreaction to oil returns is concentrated within six trading weeks. Thus, the 30 trading days (six trading weeks) horizon considered in this paper should be sufficient to uncover the extent of the predictive ability of commodities for stock returns.

Our analysis can be viewed as a test of the semi-strong form of efficient market hypothesis. In particular, we view lag lengths of greater than five trading days (one trading week) as clear evidence of "underreaction" since news announcements are impounded into stock returns at least within one trading week (Schwert, 1981; Pearce and Roley, 1985; Boyd et al., 2005).

Empirical results are reported in Table 1. These support the existence of a delayed reaction in incorporating information stemming from the commodity markets in industry returns. As White (2000) argues, many studies in time series rely on using the same data set for multiple inferences, which inexorably leads to data snooping. That is why the statistical significance of results in Table 1 are based on data-mining robust critical values (described in section 4.4) in the spirit of Rapach and Wohar (2006) and Herrera et al. (2011) and are derived from a bootstrap procedure.

Panel A of Table 1 reports the in-sample results. We recursively estimated regressions of the form of (4.2) where $j$ is between one and 30 days. The reported statistics in columns 4 to 7 report these regression results for those commodities that are statistically significant at the $10 \%$ level using the data mining robust critical values derived from a bootstrap procedure. Thus, for industry return $r_{t}^{i}$ (as in column number 2) and commodity price change $r_{t-j}{ }^{c}$ (reported in column 1), and where $j$ signifies the number of lags reported in column 3, we report estimated 
slope parameter, $\hat{\alpha}_{i, j}$ (column 4), Newey-West HAC-consistent standard errors (column 5), Robust $t$-statistics (column 6), and finally, $R^{2}$ for our predictive regression in column 7.

Panel A of Table 1 provides clear evidence of delayed reaction and can be interpreted as providing further empirical support for the underreaction or gradual information diffusion hypothesis (Hong and Stein, 1999; Hong et al., 2007). We find 147 cases of significant predictability using the data mining robust procedure. It is clear that over $85 \%$ of industries in our sample are predictable (43 out of 49 ) at more than one period ahead, given very stringent significance criteria. Further the predictors are not at all confined to a small subset of commodities; we find about $72 \%$ of commodities (18 out of 25) show evidence of significant predictability. ${ }^{20}$ Thus, there is widespread evidence of underreaction. The length of underreaction lags varies between one day (11 cases) to over 20 trading days (70 cases). The average lag length is 17.4 days and the median is 17 days. Thus, a large majority of cases have lag lengths not just larger than one trading week but larger than three trading weeks, and thus longer than much of the literature examining the response of equity prices to news (see for example, Schwert, 1981). Metals account for the bulk of evidence presented on Table 1. Further, many industries are predicted by commodities that are not directly used as their inputs. A good example is publishing (books) being led by gold base by more than 20 trading days.

While a large body of literature is focused on oil prices and stock market returns (Driesprong et al., 2008; Killian and Park, 2009; Gogineni, 2010; and Fan and Jahan-Parvar, 2012; among many others), we find that the evidence of predictability and especially delayed reaction is much

\footnotetext{
${ }^{20}$ If instead of adjusted critical values used here, we rely on conventional Student $t$-statistics based on Newey-West (1987) HAC standard errors, 40 out of 49 industries in our sample demonstrate evidence of underreaction of at least three trading weeks to information originating in commodity markets. Also, instead of 19 commodities accounting for underreaction, we have 25 commodities that demonstrate evidence of leading industries by three or more trading weeks. These results are available upon request, but are not reported to save space.
} 
stronger when we consider fluctuations in precious metal returns. For energy-related commodities (crude oil, fuel oil, propane and gasoline), we have 23 cases of predictability. In comparison, we detect 43 cases of predictability based on precious metals returns (gold and silver). We conclude that we have found a sharp difference with much of the literature, in the sense that underreaction seems more concentrated in metals and not in energy commodities. It seems that future predictability research should examine both precious metals and energy.

The fact that precious metals are so well represented in Table 1 may also be the result of their negative correlation with the business cycle and market conditions. ${ }^{21}$ Precious metals can be used as instruments to hedge against economic downturns. Thus, a positive (negative) movement in precious metal returns may signal worsening (improving) business conditions for cyclical industries such as real estate, building materials, insurance, and banking.

Based on Table 1, we contend that the speed of diffusion of information from commodity markets to equity markets is slower than the five trading days or less, which is generally observed in the news announcements literature (Boyd et al., 2005; Anderson et al., 2007). In Table 1, for precious metals 37 cases of predictability are for lag lengths greater than 10 trading days; there are 27 cases where the lag length is in excess of 20 trading days. These results suggest that the stock market, at least partly, does not immediately and fully respond to new information contained in commodity returns. In the U.S., there is no institutional barrier against the flow of information from commodity to equity markets. In fact, data on commodity movements is widely available and discussed in the financial and business press. Thus, the most plausible explanation for the slow reaction of industry stock returns (of more than five trading days; see Table 1) is the gradual diffusion of information across markets (Hong et al., 2007;

\footnotetext{
${ }^{21}$ Vrugt et al. (2004) use variables related to the business cycle and the monetary environment to build dynamic timing strategies for metals. They find there is predictable variation in futures returns, which can be exploited.
} 
Hong and Stein, 1999). Our results are especially interesting given that prior literature suggest the links between commodity and equity markets are often weak (Büyüksahin et al., 2010) and that (volatility) spillovers might flow primarily from equity market to commodity market (Malik and Hammoudeh, 2007). ${ }^{22}$

The gradual incorporation of commodity information into stock prices could also be linked to investor information processing issues and investor inattention (Hirshleifer and Teoh, 2003). Given that the link between many commodities and sector stock returns is indirect, then investors might not be immediately aware of the full importance of individual commodity log price changes for specific equity market segments. Evidence of a longer delayed stock reaction when there is an indirect link to commodities is consistent with the investor inattention hypothesis. ${ }^{23}$ For example, in Table 1, Brent predicts the oil industry returns - which it is most closely linked to - only one day ahead. However, Brent predicts the soda, building materials and business service industry returns at least 12 days ahead. ${ }^{24}$

\subsection{Out-of-Sample Forecast Ability}

\footnotetext{
${ }^{22}$ Büyüksahin et al. (2010) question how closely connected equity and commodity market are. They find evidence that correlations between the markets are time-varying and generally sufficiently weak to offer diversification benefits; however, they also note that equity and commodity markets move more closely during periods of market stress.

${ }^{23}$ Storage costs may or may not have an effect on our results. However, these costs may already be priced in some commodity markets ahead of transaction. Given that storage costs are likely heterogeneous across commodities, an exploration of the effect of storage costs on market reaction is outside the scope of this paper but a worthwhile endeavor for future extensions.

${ }^{24}$ As a demonstration for the impact of not using data-mining Student t-statistics, we present in-sample results for fuel oil based on conventional t-statistics, rather than data-mining robust values in Table A.3 (see online appendix). These results suggest that up to eight industry returns could be predicted by fuel oil at a lag length of generally more than 27 days. In contrast, Panel A of Table 1, which uses data-mining robust critical values, indicates that five industry returns underreact to fuel oil price changes and it takes 12 days for information contained in fuel oil returns to be incorporated into industry returns. Thus, the approach in Table 1 substantially reduces both the lag length and the number of times we fail to reject the underreaction null hypothesis, due to the stringent criteria we impose that explicitly accounts for data mining.
} 
Table 1 Panel B reports results for the out-of-sample performance of our model. We fit equation (4.3) to data, and use equation (4.5) as our baseline model, following Goyal and Welch (2008) in using the historical average as the baseline model. We use all lags of the commodity return up to and including those found significant for forecasting given that section 5.2 identified the maximum lag length at which predictability is apparent.

In column 8 of Table 1, we report Theil's $U$ statistic, corrected for Clark and West (2007) concerns. Since values less than unity Theil's $U$ statistic indicate superior forecast accuracy of the model investigated against a benchmark (in our case, historical average), this implies the existence of out-of-sample forecast ability for commodity returns. For $59.2 \%$ of cases (87 out of 147) we find that the adjusted Theil's $U$ is less than 1, which is considerably higher than the $50 \%$ we may expect under the null of no predictability.

Finally, in column 9 of Table 1, we report $p$-values for the Clark and West (2007) test of equal predictive accuracy. Lower $p$-values indicate that commodity price change-based forecasts have more forecasting power than historical mean-based forecasts. While we found 87 cases where the adjusted Theil's $U$ was less than 1 , only in 28 of these cases is this statistically significant according to the Clark-West test at the 10\% level. Hence only in 19\% (28 out of 147) of cases are the in-sample results of statistical predictability corroborated in the out-of-sample tests. This is more than the $10 \%$ of cases we would anticipate to find purely by chance. We conjecture that the differences between the in-sample and out-of-sample results could be due to i) a change in the financial markets since our sample start date of 1985, ii) the existence of outliers and/or iii) in-sample tests possibly being more powerful than out-of-sample tests (Inoue and Kilian, 2005). We provide empirical analysis related to points i) and ii) and discuss point iii). 


\section{Robustness}

In this section we provide further analysis of underreaction to help us better understand the in-sample and out-of-sample tests reported in Section 5. The first issue we examine is whether the sample period impacts the out-of-sample results. Arguably, financial markets changed dramatically between the mid-1980s and the end of the millennium with huge increases in trading volumes and liquidity. Hence the early part of the sample may not be so useful in identifying in-sample relationships that are still apparent today. Terefore, in Table 2 we re-run our underreaction tests from Table 1 by changing the start date for the in-sample period from January 1985 to January $2000 .^{25}$

The main results in Table 2 (post-2000 out-of-sample) show similar numbers of cases of insample predictability to Table 1 (141 versus 147). Some of the other results are broadly consistent with Table 1. For example, average lag length is more than three weeks at 20 days and median lag length is now 23 days, both of which remain much longer than would be generally considered consistent with market efficiency. Metals, especially precious metals feature even more prominently for the post-2000 sample (Table 2) and remain much more important than energy commodities, whereas agricultural and non-metal industrial commodities are only evident in a small number of cases. However, other results are much weaker. The out-of-sample results in terms of the Clark-West test are weaker compared to Table 1. For the post-2000 sample we find about $2 \%$ of cases ( 3 out of 141 ) are statistically significant, which is dramatically less than the $10 \%$ of cases you would expect under the null of no predictability and the $19 \%$ of cases we reported in Table 1. The proportion of cases where Theil's $U$ is less than 1 is also dramatically

\footnotetext{
${ }^{25}$ While we use spot prices in this paper, one other justification for our sample split in 200 is the Commodity Futures Modernization Act (CFMA) of 2000.
} 
lower at about 37\%, substantially less than the 50\% anticipated under the null of no predictability. ${ }^{26}$

Finally, Inoue and Kilian (2005) point out that out-of-sample tests may not be superior to insample tests. In particular, in theoretical analysis they demonstrate that out-of-sample tests can be less powerful than in-sample tests. It is also the case that either the in-sample test or the outof-sample test could falsely reject the null. Consequently, it can be anticipated that out-of-sample tests will not fully corroborate in-sample tests due to these two factors. Nevertheless, that we find some cases where both in-sample and out-of-sample results indicate that predictability does exist strongly suggests that predictability of stock returns by commodities cannot be fully attributed to data mining.

\section{Concluding remarks}

This study provides further evidence on the delayed reaction hypothesis of Hong and Stein (1999). We use a variation of Hong et al. (2007) slow diffusion of information methodology and implement procedures to account for data mining, building upon Herrera et al. (2011). We examine the relationship between a wide range of different commodities and industry stock returns. The paper primarily extends the literature in three directions. First, related prior work examines whether there is a delayed reaction to information. In contrast, this paper aims to identify how long it takes for information to be fully incorporated into prices. Second, prior research focuses on information that has a direct economic link to stock returns, but this paper

\footnotetext{
${ }^{26}$ For robustness, we re-estimated our model with a second sample that excluded observations that were five standard deviations from the mean. Both samples yielded a similar number of cases of in-sample predictability. Conversely, the median lag length in the second was dramatically reduced compared to results in Table 1 . Our results suggest that extreme returns partly drive the long lag lengths. A table with those results is available upon request.
} 
additionally provides a widespread investigation of information with only indirect links to stock returns. Third, we are one of the first studies in the delayed reaction literature to explicitly account for data mining and to investigate out-of-sample forecasting power.

One key improvement over that of previous literature is that we measure the specific length of time for commodity price information to be fully incorporated into stock prices. To meet this objective, we use daily data and examine a much broader range of commodities. Empirical results indicate that a large sub-sample of commodities predict industry stock returns. There is evidence that it can take more than two trading weeks (and often more than four trading weeks) for commodity information to be fully incorporated into stock returns, indicating that there is a substantial delay before information originating in commodity markets is fully incorporated into asset prices. We also find that some of the longer delayed reaction can be attributed to outlying observations. Nonetheless, the length of delay is substantially longer than for news announcements, which tends to be incorporated into asset prices within a week (Schwert, 1981; Boyd et al., 2005). These results imply that traders have limited information processing power or sometimes neglect relevant information. Thus, our evidence lends support for the gradual diffusion of information that was introduced by Hong and Stein (1999) and Hong et al. (2007).

We also provide evidence that many commodities Granger cause a wide range of other commodity prices. In particular, we find that precious metals Granger cause almost all other commodities reported in this study. These results provide new and novel evidence of gradual information diffusion within the commodity market that extends prior findings of delayed reaction within the equity market (Hong et al., 2007).

This paper documents the extent of underreaction in industry returns to information contained by commodity prices. We provide empirical evidence that there are cases of 
substantial delays in response to this information, which cannot be fully explained by data mining. While out-of-sample predictability is not especially strong, we interpret this result to be in line with Inoue and Kilian (2005) who find that in-sample tests are more powerful than out-ofsample tests. We do not attempt to place a deep economic interpretation on our results, as identification of the source of shocks to commodity prices is beyond the scope of our investigation. Future research could investigate more fully how particular types of commodity shocks might affect the link between non-energy commodities and industry stock returns. 


\section{References}

Andersen, T. G., Bollerslev, T., Diebold, F., and C. Vega, 2007. Real-time price discovery in global stock, bond and foreign exchange markets. Journal of International Economics, 73, 251-277

Ball, R., and P. Brown, 1968. An Empirical Evaluation of Accounting Income Numbers, Journal of Accounting Research, 6, 159-178

Barberis, N., and R. Thaler, 2003. A Survey of Behavioral Finance. In: G. Constantinides, R. Stulz and M. Harris (eds.): Handbook of the Econonomics of Finance. North Holland.

Boyd, J.H., Hu, J., and R. Jagannathan, 2005. The stock market's reaction to unemployment news: Why bad news is usually good for stocks, Journal of Finance, 60 (2), 649-672.

Brunetti, C., B. Büyüksahin, M. Robe, and K. Soneson, 2010. Do OPEC Members Know Something the Market Doesn't? 'Fair Price' Pronouncements and the Market Price of Crude Oil, mimeo.

Busse, J. and T.C. Green, 2002. Market Efficiency in Real Time, Journal of Financial Economics 65, 413-437.

Büyüksahin, B., M. Haigh, and M. Robe 2010. Commodities and Equities: Ever A 'Market of One'? Journal of Alternative Investment 12, 76-95.

Chaboud, A., B. Chiquoine, E. Hjalmarsson, and C. Vega 2014. Rise of the machines: Algorithmic trading in foreign exchange market. Journal of Finance, 69 (5), 2045-2084.

Clark, T. E., and K. D. West, 2007. Approximately Normal Tests for Equal Forecast Accuracy in Nested Models. Journal of Econometrics, 138:291-311.

Colling, P.L. and S.H. Irwin, 1990. The Reaction of Live Hog Futures Prices to USDA Hogs and Pigs Reports. American Journal of Agricultural Economics, 72 (1), 84-94.

Chng, M. T., 2009. Economic linkages across commodity futures: Hedging and trading implications. Journal of Banking \& Finance 33 (5) 958-970.

Driesprong, G., Jacobsen, B., and B. Maat, 2008. Striking oil: Another puzzle? Journal of Financial Economics 89, 307-327.

Fama, E. and French, K. 1988. Business Cycles and the Behavior of Metals Prices. The Journal of Finance 43 (5) 1075-1093

Fan, Q., and M. R. Jahan-Parvar, 2012. US industry-level returns and oil prices. International Review of Economics \& Finance 22(1), 112-128.

Gorton, G., and K.G. Rouwenhorst, 2006. Facts and Fantasies About Commodity Futures, Financial Analysts Journal, 62 (2), 47-68.

Granger, C. W. J., 1969. Investigating causal relations by econometric models and cross-spectral methods. Econometrica 37 (3), 424-438.

Gogineni, S., 2010. Oil and the stock market: An industry level analysis. Financial Review 45 (4) 995-1010.

Goyal, A., and I. Welch, 2008. A comprehensive look at the empirical performance of equity premium prediction. Review of Financial Studies 21, 1455-1508.

Hamilton, J. D., 1983. Oil and the macroeconomy since World War II. Journal of Political Economy, 91, 228248.

Harri. A., Nalley, L., and D. Hudson, 2009. The Relationship between Oil, Exchange Rates, and Commodity Prices, Journal of Agricultural and Applied Economics, 41, 501-510. 
Herrera, A. M., Lagalo, L. G., and T. Wada, 2011. Oil Price Shocks and Industrial Production: Is the Relationship Linear? Macroeconomic Dynamics, 15(S3), 472-497.

Hirshleifer, D., 2008. Investor Psychology and Asset Pricing, Journal of Finance, 58, 1533-1598

Hirshleifer, D., and S.H. Teoh. Limited Attention, Information Disclosure, and Financial Reporting. Journal of Accounting and Economics, 36, 337-386.

Hirshleifer, D., and S.H. Teoh, 2005. Limited Investor Attention and Stock Market Misreactions to Accounting Information. Working Paper, the Ohio State University.

Hong, H., Stein, J., 1999. A unified theory of underreaction, momentum trading and overreaction in asset markets. Journal of Finance 54, 2143-2148.

Hong, H., Torous, W., and R. Valkanov, 2007. Do industries lead stock markets? Journal of Financial Economics 83, 367-396.

Huang, R. D., Masulis, R. W., Roll, H. R., 1996. Energy shocks and financial markets. The Journal of Futures Markets 16(1), 1-27.

Inoue A., and Kilian, L., 2005. In-sample or out-of-sample tests of predictability: Which one should we use? Econometric Reviews, 23, 371-402.

Jacobsen, B., B.R. Marshall, and N. Visaltanachoti, 2010. State-Switching Return Predictability, Working paper.

Jegadeesh, N., and S. Titman, 1993. Returns to buying winners and selling losers: Implications

for stock market efficiency, Journal of Finance 48, 65-91.

Kilian, L., 2009. Not all oil price shocks are alike: Disentangling demand and supply shocks in the crude oil market. American Economic Review, 99(3), 1053-1069.

Kilian, L., and C. Park, 2009. The Impact of Oil Price Shocks on the U.S. Stock Market. International Economic Review, 50(4), November 2009, 1267-1287.

Kilian, L. and C. Vega 2011. Do Energy Prices Respond to U.S. Macroeconomic News? A Test of the Hypothesis of Predetermined Energy Prices The Review of Economics and Statistics 93, 660-671.

Malik, F. and S. Hammoudeh, 2007. Shock and volatility transmission in the oil, US and Gulf equity markets, International Review of Economics and Finance, 16, 357-68.

Merton, R., 1987. A simple model of capital market equilibrium with incomplete information. Journal of Finance 42, 483-510.

Milonas, N., 1987. The effects of USDA crop announcements on commodity prices, Journal of Futures Markets, 7, 571-589.

Newey, W. K. and K. D. West, 1987. A simple, positive semi-definite, heteroskedasticity and autocorrelation consistent covariance matrix. Econometrica, 55, 703-708.

Pearce, D.K. and V.V. Roley, 1985. Stock Prices and Economic News, Journal of Business, 58, 49-67.

Rapach, D.E. and M.E. Wohar, 2006. In-sample vs. out-of-sample tests of stock return predictability in the context of data mining. Journal of Empirical Finance, 13(2), pp.231-247.

Schwert, G.W., 1981. The Adjustment of Stock Prices to Information About Inflation. Journal of Finance, 36, (1), 15-29.

Shiller, R. J., 2000. Measuring bubble expectations and investor confidence. Journal of Psychology and Financial Markets 1 (1), 49-60.

Sims, C., 1972. Money, income, and causality. American Economic Review 62 (4), 540-552. 
Sims, C., 2003. Implications of rational inattention. Journal of Monetary Economics, 50(3), 665-690.

Theil, H. 1971. Applied Economic Forecasting. Amsterdam, the Netherlands: North Holland.

Vivian, A., Wohar, M.E., 2012. Commodity volatility breaks. Journal of International Financial Markets, Institutions, and Money, 22(2), 395-422.

Vrugt, E.B., Bauer, R., Molenaar R., Stemkamp, T., 2004. Dynamic Commodity Timing Strategies, Working paper.

White, H., 2000. A reality check for data snooping. Econometrica 68(5), 1097-1128. 
Table 1: Underreaction in Industry Returns

\begin{tabular}{|c|c|c|c|c|c|c|c|c|}
\hline \multirow[b]{2}{*}{ Commodity } & \multirow[b]{2}{*}{ Industry } & \multirow[b]{2}{*}{ Lags } & \multicolumn{4}{|c|}{ Panel A: In-Sample Results (1985-2010) } & \multicolumn{2}{|c|}{ Panel B: Out-of-Sample Results } \\
\hline & & & Slope & $\begin{array}{c}\text { NW St } \\
\text { Err }\end{array}$ & Robust $t$-Stat & $\begin{array}{c}\text { R- } \\
\text { Squared }\end{array}$ & Theil's Adi. U & CW p-value \\
\hline Brent & Soda & 17 & -0.0310 & 0.0085 & -3.636 & 0.2018 & 0.9943 & 0.0705 \\
\hline Brent & BldMt & 28 & -0.0254 & 0.0069 & -3.655 & 0.2042 & 1.0117 & 0.9221 \\
\hline Brent & Oil & 1 & 0.0325 & 0.0076 & 4.297 & 0.2809 & 0.9985 & 0.3114 \\
\hline WTI & Cnstr & 11 & -0.0348 & 0.0087 & -4.017 & 0.2460 & 0.9961 & 0.3070 \\
\hline WTI & Insur & 1 & -0.0325 & 0.0065 & -5.017 & 0.3826 & 0.9945 & 0.1339 \\
\hline FuelOil & Txtls & 12 & -0.0315 & 0.0074 & -4.281 & 0.2793 & 0.9975 & 0.3628 \\
\hline FuelOil & Gold & 10 & 0.0461 & 0.0119 & 3.878 & 0.2293 & 0.9941 & 0.2337 \\
\hline Propane & MedEq & 12 & -0.0222 & 0.0062 & -3.610 & 0.1987 & 0.9906 & 0.0572 \\
\hline Propane & Chems & 7 & 0.0245 & 0.0069 & 3.535 & 0.1905 & 1.0048 & 0.7560 \\
\hline Propane & Cnstr & 12 & -0.0311 & 0.0088 & -3.528 & 0.1899 & 0.9922 & 0.1448 \\
\hline Propane & Ships & 12 & -0.0275 & 0.0073 & -3.746 & 0.2140 & 0.9872 & 0.0616 \\
\hline Propane & Softw & 12 & -0.0314 & 0.0089 & -3.528 & 0.1898 & 0.9898 & 0.0589 \\
\hline Propane & Whlsl & 12 & -0.0217 & 0.0054 & -3.993 & 0.2431 & 0.9912 & 0.0771 \\
\hline Propane & Meals & 12 & -0.0224 & 0.0063 & -3.582 & 0.1958 & 0.9927 & 0.1181 \\
\hline Propane & Banks & 21 & -0.0304 & 0.0085 & -3.575 & 0.1952 & 0.9969 & 0.3877 \\
\hline WheatNo2 & Coal & 9 & 0.0647 & 0.0183 & 3.529 & 0.1899 & 0.9841 & 0.0280 \\
\hline WheatNo2 & Banks & 25 & 0.0442 & 0.0122 & 3.619 & 0.2002 & 1.0209 & 0.9587 \\
\hline WheatNo2 & RlEst & 19 & 0.0419 & 0.0113 & 3.715 & 0.2107 & 1.0000 & 0.4980 \\
\hline WheatNo2 & Fin & 25 & 0.0462 & 0.0127 & 3.638 & 0.2022 & 1.0195 & 0.9707 \\
\hline SpringWheat & Mines & 23 & 0.0434 & 0.0117 & 3.723 & 0.2118 & 0.9982 & 0.4454 \\
\hline SpringWheat & Coal & 13 & -0.0630 & 0.0169 & -3.735 & 0.2128 & 0.9933 & 0.2997 \\
\hline Oats & Books & 6 & -0.0292 & 0.0073 & -3.991 & 0.2426 & 1.0093 & 0.8546 \\
\hline Oats & Txtls & 18 & 0.0319 & 0.0085 & 3.736 & 0.2131 & 1.0160 & 0.9194 \\
\hline Oats & FabPr & 8 & -0.0326 & 0.0089 & -3.653 & 0.2034 & 0.9832 & 0.0621 \\
\hline Oats & Autos & 8 & -0.0367 & 0.0091 & -4.051 & 0.2501 & 0.9885 & 0.2082 \\
\hline Oats & Gold & 5 & -0.0485 & 0.0137 & -3.528 & 0.1897 & 1.0020 & 0.5836 \\
\hline Oats & BusSv & 6 & -0.0232 & 0.0065 & -3.537 & 0.1907 & 1.0082 & 0.8980 \\
\hline Oats & Chips & 6 & -0.0395 & 0.0103 & -3.820 & 0.2223 & 1.0078 & 0.9326 \\
\hline Oats & Banks & 6 & -0.0416 & 0.0092 & -4.508 & 0.3094 & 1.0049 & 0.6908 \\
\hline Oats & Insur & 14 & -0.0287 & 0.0072 & -4.005 & 0.2446 & 0.9932 & 0.2114 \\
\hline Oats & RlEst & 6 & -0.0392 & 0.0085 & -4.594 & 0.3212 & 1.0155 & 0.8848 \\
\hline
\end{tabular}




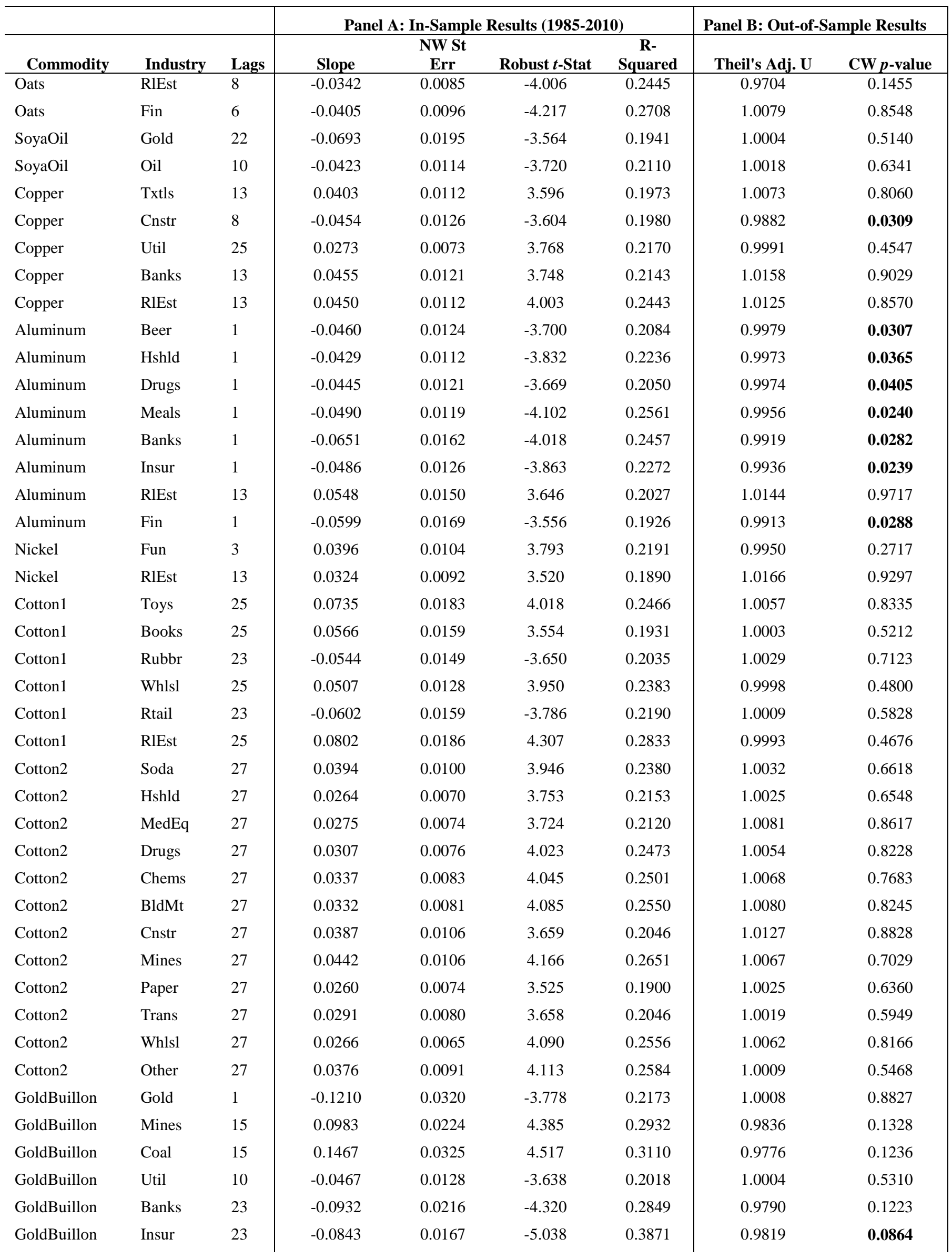




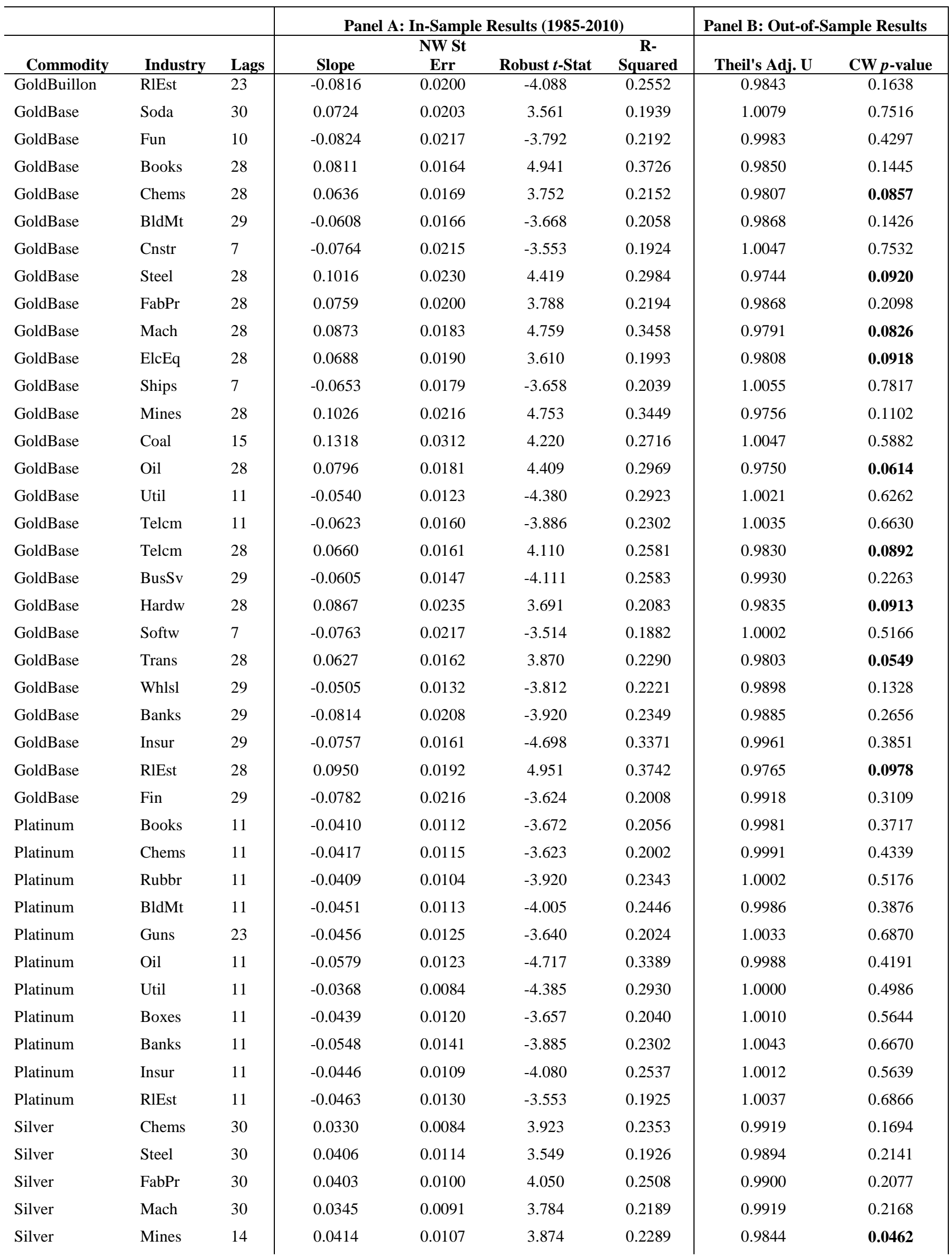




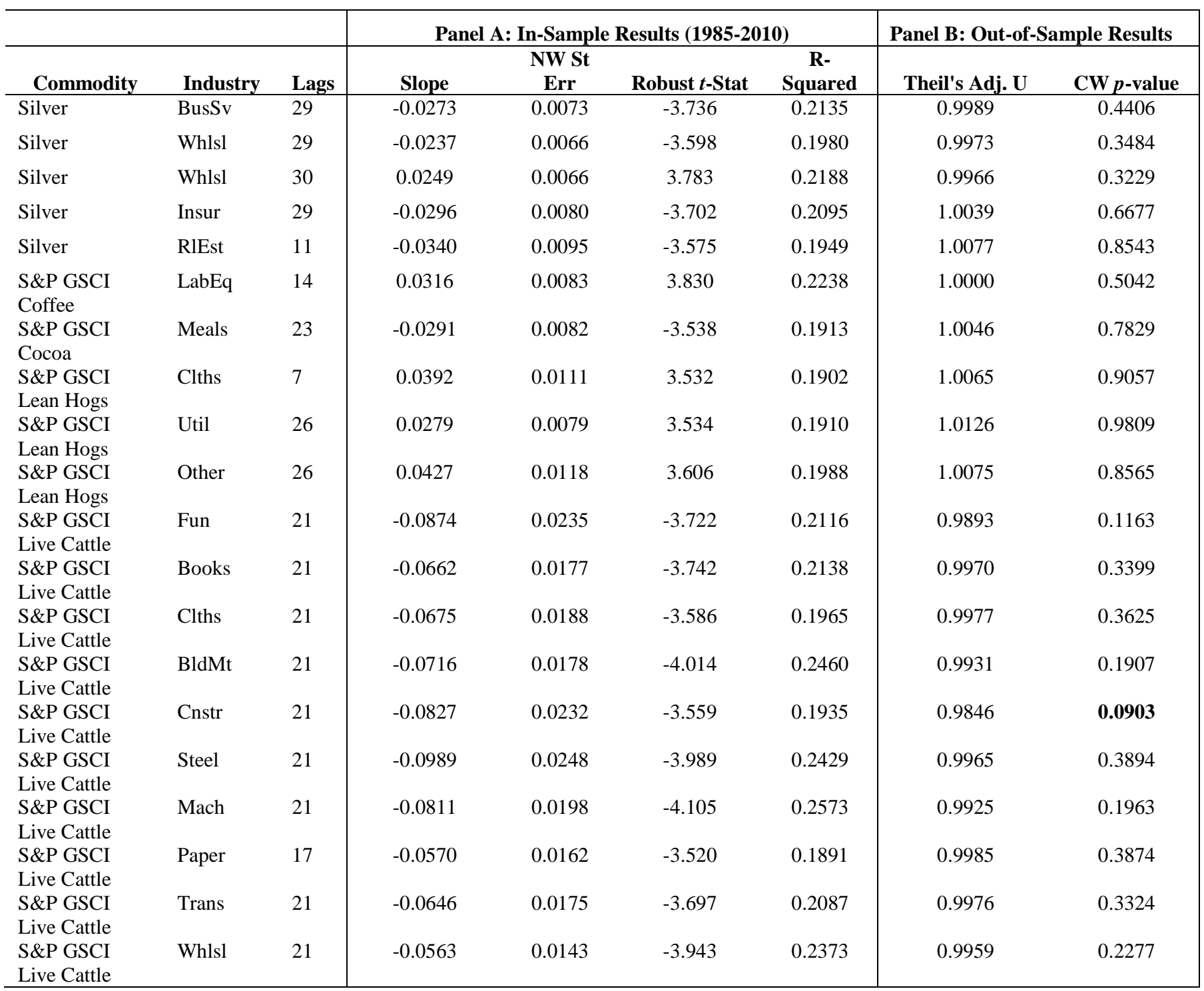

Notes: Table 1 presents the results for underreaction and out-of-sample predictability tests, discussed in Sections 4.2-4.4, for the full sample period. The first column denotes the commodity log price changes used for testing, the second column reports the industry return (dependent variable), the third column denotes the lag length of the commodity return included in the regression. Columns 4-7, corresponding to Panel A, report the estimated coefficient for the commodity return, the Newey-West standard error, the Robust $t$-statistics, and the coefficient of determination, respectively.

The Robust $t$-statistic corresponds to tests that reject the null hypothesis of no predictability at $10 \%$ or smaller based on the correction method of Rapach and Wohar (2006) and Herrera, et al. (2011) which address data-mining concerns. Using this methodology, absolute critical values are 3.5132. The lag length reported was determined by regressing the industry return on individual lagged values of the commodity returns starting from lag 1 and up to lag 30 and recording the longest individual lagged return that is statistically significant, given the adjusted critical values. The reported results are based from regressions of Equation 4.2: $r_{t}^{i}=\mu_{i, j}+\alpha_{i, j} r_{t-j}^{c}+\varepsilon_{t}^{i}$ where $r_{t}^{i}$ is industry $i$ 's returns,

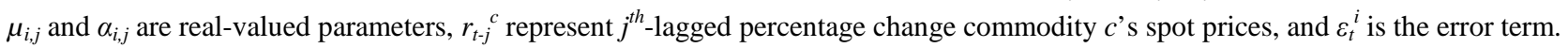
For the out-of-sample part we want to know how much forecast power there is from all lags up to the maximal significant lag length (S). Hence we estimate multivariate regressions of Equation 4.3: $r_{t+m}^{i}=\mu_{i, j}+\sum_{j=1}^{S} \alpha_{i, j} r_{t-j}^{c}+\varepsilon_{t+m}^{i}$. over a five year rolling window to estimate the co-efficient values for the forecast, which are then used to generate the forecasts using equation 4.4. Column 8 under Panel B reports the adjusted Theil's U and Column 9 reports the p-value of the Clark-West (2007) test statistic; both these measures adjust for the parameter uncertainty associated with estimating the alternative model under the assumption of no predictability. 
Table 2: Underreaction in Industry Returns (Post-2000)

\begin{tabular}{|c|c|c|c|c|c|c|c|c|}
\hline \multirow[b]{2}{*}{ Commodity } & \multirow[b]{2}{*}{ Industry } & \multirow[b]{2}{*}{ Lags } & \multicolumn{4}{|c|}{ Panel A: In-Sample Results (2000-2010) } & \multicolumn{2}{|c|}{ Panel B: Out-of-Sample Results } \\
\hline & & & Slope & $\begin{array}{l}\text { NW St } \\
\text { Err }\end{array}$ & Robust $t$-Stat & $\begin{array}{c}\text { R- } \\
\text { Squared }\end{array}$ & Theil's Adj. U & CW p-value \\
\hline PorkBelly & Hlth & 26 & -0.0259 & 0.0069 & -3.760 & 0.5157 & 1.0027 & 0.6863 \\
\hline PorkBelly & Txtls & 26 & -0.0351 & 0.0099 & -3.550 & 0.4598 & 1.0189 & 0.9771 \\
\hline WTI & Hshld & 1 & -0.0334 & 0.0092 & -3.628 & 0.4759 & 1.0010 & 0.6458 \\
\hline WTI & Drugs & 5 & -0.0358 & 0.0095 & -3.766 & 0.5132 & 1.0019 & 0.6762 \\
\hline WTI & Boxes & 8 & -0.0463 & 0.0122 & -3.807 & 0.5252 & 1.0000 & 0.5018 \\
\hline WTI & Banks & 13 & 0.0589 & 0.0166 & 3.544 & 0.4561 & 1.0168 & 0.9286 \\
\hline WTI & Insur & 1 & -0.0571 & 0.0126 & -4.525 & 0.7381 & 1.0024 & 0.6806 \\
\hline WTI & RlEst & 13 & 0.0533 & 0.0153 & 3.484 & 0.4408 & 1.0107 & 0.8318 \\
\hline WTI & RlEst & 27 & 0.0537 & 0.0153 & 3.505 & 0.4485 & 0.9629 & 0.0159 \\
\hline WTI & Fin & 16 & 0.0677 & 0.0175 & 3.860 & 0.5411 & 0.9991 & 0.4718 \\
\hline FuelOil & Hshld & 29 & 0.0309 & 0.0080 & 3.856 & 0.5426 & 1.0025 & 0.6614 \\
\hline FuelOil & Gold & 10 & 0.0629 & 0.0178 & 3.522 & 0.4500 & 1.0068 & 0.7694 \\
\hline FuelOil & Banks & 13 & 0.0530 & 0.0146 & 3.627 & 0.4775 & 1.0280 & 0.9717 \\
\hline Propane & Drugs & 7 & 0.0342 & 0.0097 & 3.529 & 0.4513 & 1.0086 & 0.9606 \\
\hline Propane & Chems & 7 & 0.0462 & 0.0131 & 3.518 & 0.4486 & 1.0139 & 0.9848 \\
\hline Propane & Gold & 2 & -0.0748 & 0.0207 & -3.617 & 0.4731 & 0.9861 & 0.0429 \\
\hline Propane & Oil & 5 & -0.0592 & 0.0139 & -4.266 & 0.6578 & 0.9880 & 0.0567 \\
\hline Gasoline & Cnstr & 16 & 0.0465 & 0.0133 & 3.509 & 0.4478 & 1.0110 & 0.8340 \\
\hline Gasoline & Ships & 16 & 0.0369 & 0.0098 & 3.778 & 0.5185 & 1.0015 & 0.5873 \\
\hline Gasoline & Banks & 13 & 0.0518 & 0.0131 & 3.964 & 0.5701 & 1.0074 & 0.6983 \\
\hline Gasoline & Insur & 13 & 0.0361 & 0.0099 & 3.638 & 0.4805 & 1.0024 & 0.5891 \\
\hline Gasoline & RlEst & 13 & 0.0460 & 0.0120 & 3.830 & 0.5324 & 0.9975 & 0.4280 \\
\hline Gasoline & Fin & 16 & 0.0484 & 0.0138 & 3.511 & 0.4482 & 1.0075 & 0.6864 \\
\hline WheatNo2 & Rubbr & 24 & -0.0575 & 0.0144 & -3.999 & 0.5823 & 1.0059 & 0.8045 \\
\hline Oats & Books & 6 & -0.0452 & 0.0118 & -3.823 & 0.5290 & 0.9960 & 0.2755 \\
\hline Oats & Books & 10 & 0.0455 & 0.0118 & 3.860 & 0.5400 & 1.0163 & 0.9707 \\
\hline Oats & ElcEq & 10 & 0.0522 & 0.0133 & 3.926 & 0.5586 & 1.0101 & 0.9174 \\
\hline Oats & Gold & 5 & -0.1054 & 0.0198 & -5.326 & 1.0214 & 0.9918 & 0.2626 \\
\hline Oats & Telcm & 6 & -0.0413 & 0.0116 & -3.563 & 0.4598 & 0.9980 & 0.3391 \\
\hline Oats & BusSv & 6 & -0.0373 & 0.0106 & -3.516 & 0.4478 & 0.9976 & 0.3207 \\
\hline Oats & Chips & 6 & -0.0619 & 0.0173 & -3.588 & 0.4664 & 0.9985 & 0.3741 \\
\hline Oats & Banks & 10 & 0.0589 & 0.0163 & 3.625 & 0.4765 & 1.0170 & 0.9252 \\
\hline Oats & Insur & 14 & -0.0463 & 0.0124 & -3.746 & 0.5096 & 1.0028 & 0.6183 \\
\hline Oats & RlEst & 6 & -0.0780 & 0.0149 & -5.235 & 0.9874 & 0.9929 & 0.2604 \\
\hline Oats & Fin & 10 & 0.0626 & 0.0171 & 3.650 & 0.4832 & 1.0172 & 0.9530 \\
\hline Oats & Other & 18 & 0.0448 & 0.0127 & 3.539 & 0.4557 & 0.9971 & 0.3570 \\
\hline SoyaOil & LabEq & 24 & -0.0832 & 0.0212 & -3.920 & 0.5596 & 1.0021 & 0.6222 \\
\hline Copper & Rubbr & 13 & 0.0539 & 0.0145 & 3.716 & 0.5012 & 0.9997 & 0.4840 \\
\hline Copper & Txtls & 13 & 0.0777 & 0.0196 & 3.970 & 0.5717 & 0.9996 & 0.4821 \\
\hline Copper & Guns & 13 & 0.0583 & 0.0161 & 3.623 & 0.4765 & 0.9989 & 0.4435 \\
\hline Copper & Util & 25 & 0.0469 & 0.0127 & 3.706 & 0.5007 & 0.9973 & 0.3640 \\
\hline
\end{tabular}




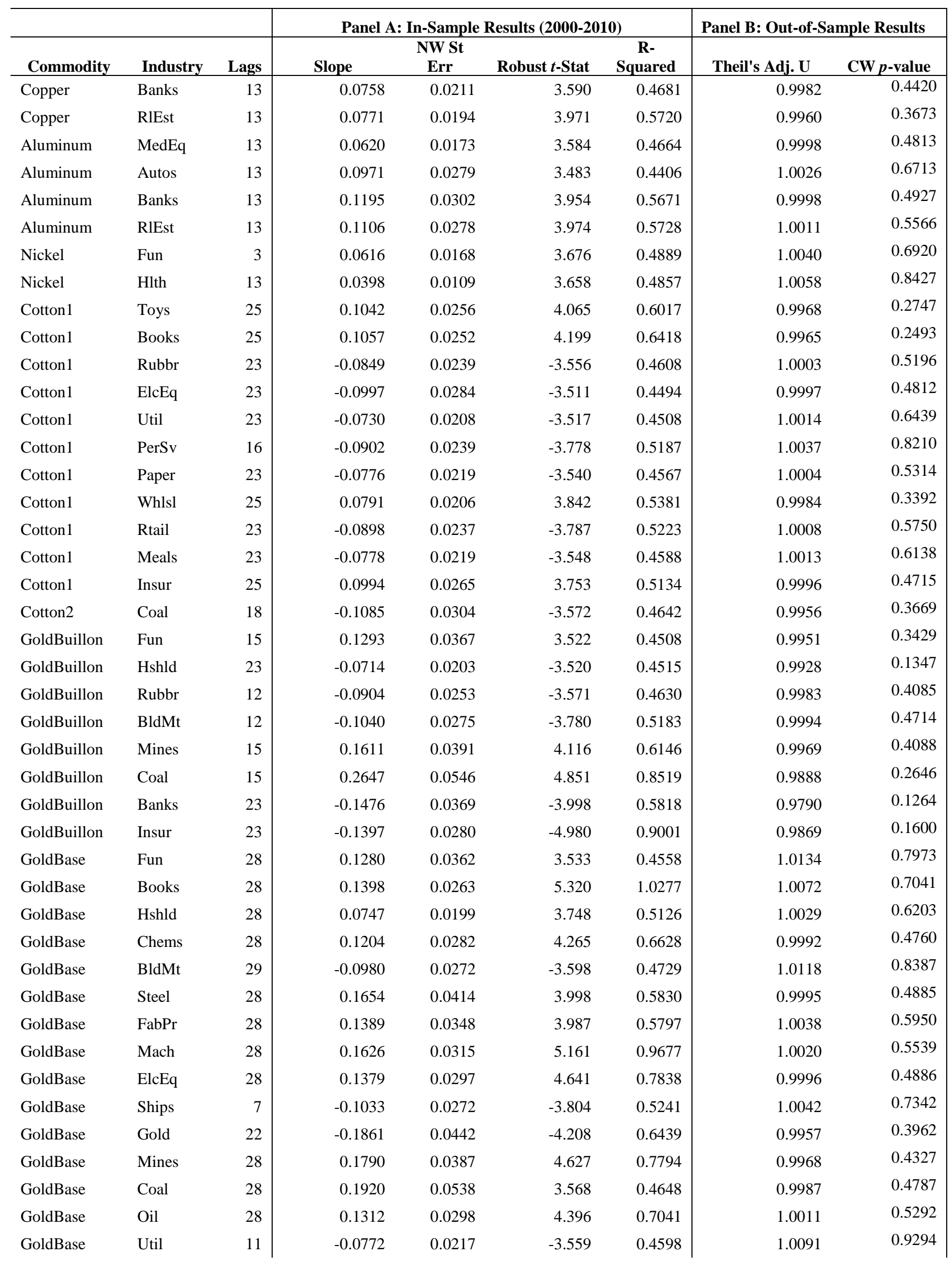




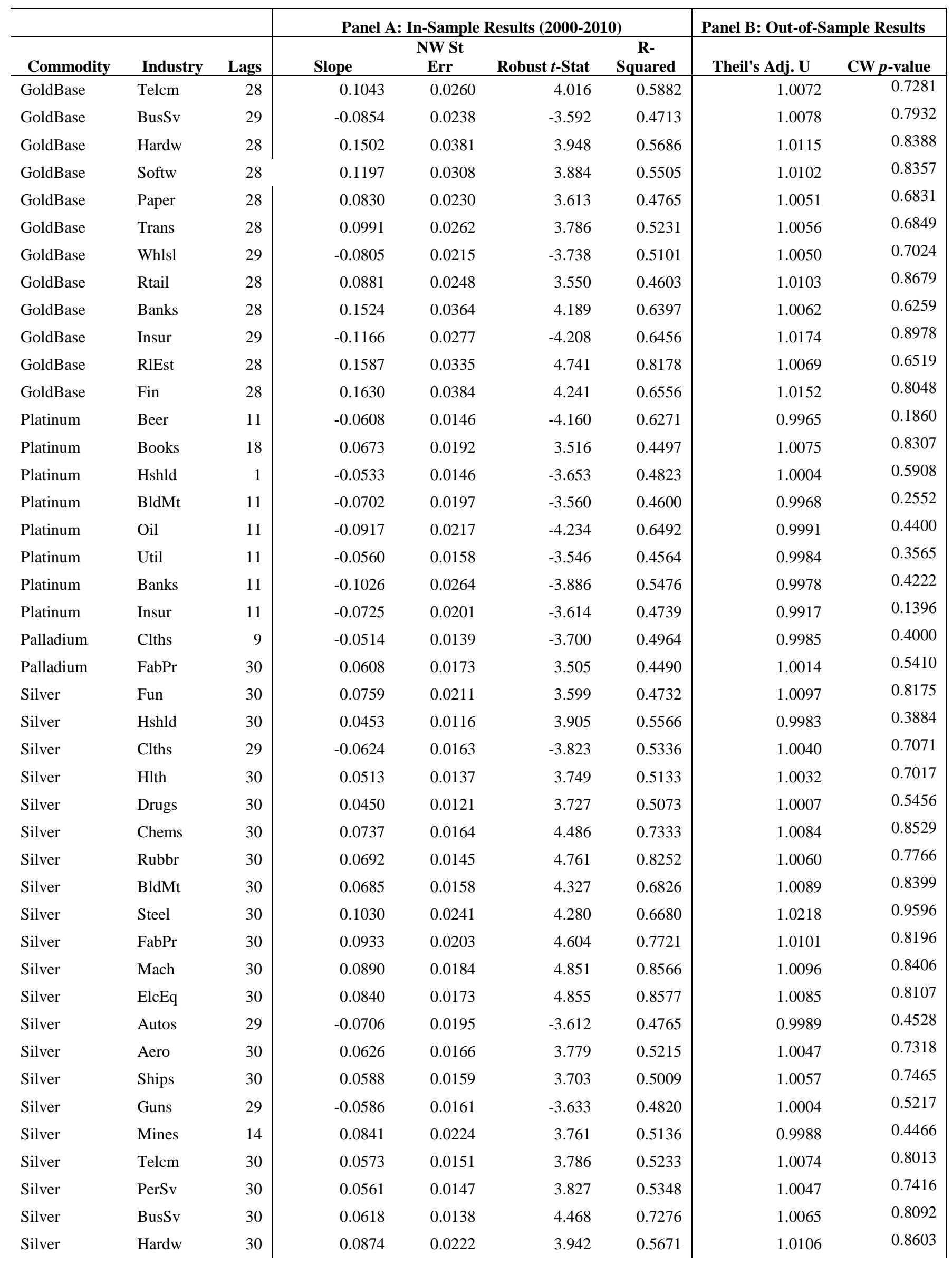




\begin{tabular}{|c|c|c|c|c|c|c|c|c|}
\hline \multirow[b]{2}{*}{ Commodity } & \multirow[b]{2}{*}{ Industry } & \multirow[b]{2}{*}{ Lags } & \multicolumn{4}{|c|}{ Panel A: In-Sample Results (2000-2010) } & \multicolumn{2}{|c|}{ Panel B: Out-of-Sample Results } \\
\hline & & & Slope & $\begin{array}{l}\text { NW St } \\
\text { Err }\end{array}$ & Robust $t$-Stat & $\begin{array}{c}\text { R- } \\
\text { Squared }\end{array}$ & Theil's Adj. U & CW p-value \\
\hline Silver & Softw & 30 & 0.0657 & 0.0180 & 3.659 & 0.4891 & 1.0058 & 0.7691 \\
\hline Silver & Chips & 30 & 0.1007 & 0.0225 & 4.484 & 0.7326 & 1.0059 & 0.7365 \\
\hline Silver & LabEq & 30 & 0.0771 & 0.0183 & 4.205 & 0.6450 & 1.0068 & 0.8191 \\
\hline Silver & Paper & 30 & 0.0550 & 0.0134 & 4.113 & 0.6171 & 1.0056 & 0.7981 \\
\hline Silver & Boxes & 30 & 0.0751 & 0.0155 & 4.847 & 0.8549 & 1.0023 & 0.6102 \\
\hline Silver & Trans & 30 & 0.0662 & 0.0152 & 4.349 & 0.6894 & 1.0077 & 0.8335 \\
\hline Silver & Whlsl & 30 & 0.0628 & 0.0125 & 5.024 & 0.9181 & 1.0057 & 0.7828 \\
\hline Silver & Meals & 30 & 0.0594 & 0.0134 & 4.445 & 0.7201 & 1.0062 & 0.8288 \\
\hline Silver & Banks & 29 & -0.0798 & 0.0212 & -3.765 & 0.5175 & 1.0005 & 0.5196 \\
\hline Silver & Insur & 29 & -0.0668 & 0.0161 & -4.146 & 0.6267 & 1.0005 & 0.5230 \\
\hline Silver & RlEst & 29 & -0.0689 & 0.0195 & -3.528 & 0.4546 & 0.9991 & 0.4650 \\
\hline Silver & Fin & 29 & -0.0840 & 0.0224 & -3.750 & 0.5134 & 0.9994 & 0.4766 \\
\hline Sugar & Chems & 5 & -0.0291 & 0.0083 & -3.519 & 0.4484 & 1.0013 & 0.5948 \\
\hline Сосоа & Meals & 30 & -0.0577 & 0.0140 & -4.136 & 0.6241 & 1.0012 & 0.5755 \\
\hline $\begin{array}{l}\text { S\&P GSCI } \\
\text { Lean Hogs }\end{array}$ & Hlth & 28 & 0.0579 & 0.0163 & 3.546 & 0.4591 & 1.0040 & 0.7151 \\
\hline
\end{tabular}

Notes: Table 2 presents the results for underreaction and out-of-sample predictability tests, discussed in Sections 4.2-4.4, for the full sample period. The first column denotes the commodity log price changes used for testing, the second column reports the industry return (dependent variable), the third column denotes the lag length of the commodity return included in the regression. Columns 4-7, corresponding to Panel A, report the estimated coefficient for the commodity return, the Newey-West standard error, the Robust $t$-statistics, and the coefficient of determination, respectively.

The Robust $t$-statistic corresponds to tests that reject the null hypothesis of no predictability at $10 \%$ or smaller, based on the correction method of Rapach and Wohar (2006) and Herrera, et al. (2011) which address data-mining concerns. Using this methodology, absolute critical values are 3.482. The lag length reported was determined by regressing the industry return on individual lagged values of the commodity returns starting from lag 1 and up to lag 30 and recording the longest individual lagged return that is statistically significant, given the adjusted critical values. The reported results are based from regressions of Equation 4.2: $r_{t}^{i}=\mu_{i, j}+\alpha_{i, j} r_{t-j}^{c}+\varepsilon_{t}^{i}$ where $r_{t}^{i}$ is

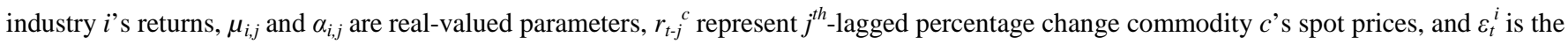
error term.

For the out-of-sample part we want to know how much forecast power there is from all lags up to the maximal significant lag length (S).

Hence, we estimate multivariate regressions of Equation 4.3: $r_{t+m}^{i}=\mu_{i, j}+\sum_{j=1}^{S} \alpha_{i, j} r_{t-j}^{c}+\varepsilon_{t+m}^{i}$. over a five year rolling window to

estimate the co-efficient values for the forecast, which are then used to generate the forecasts. Column 8 under Panel B reports the adjusted Theil's U and Column 9 reports the p-value of the Clark-West (2007) test statistic; both these measures adjust for the parameter uncertainty associated with estimating the alternative model under the assumption of no predictability. The reported results in Panel B are estimated from equation 4.3 where S corresponds to the maximal lag length found to be significant. 
Figure 1: Granger-Causality Tests Length of Delayed Reaction.
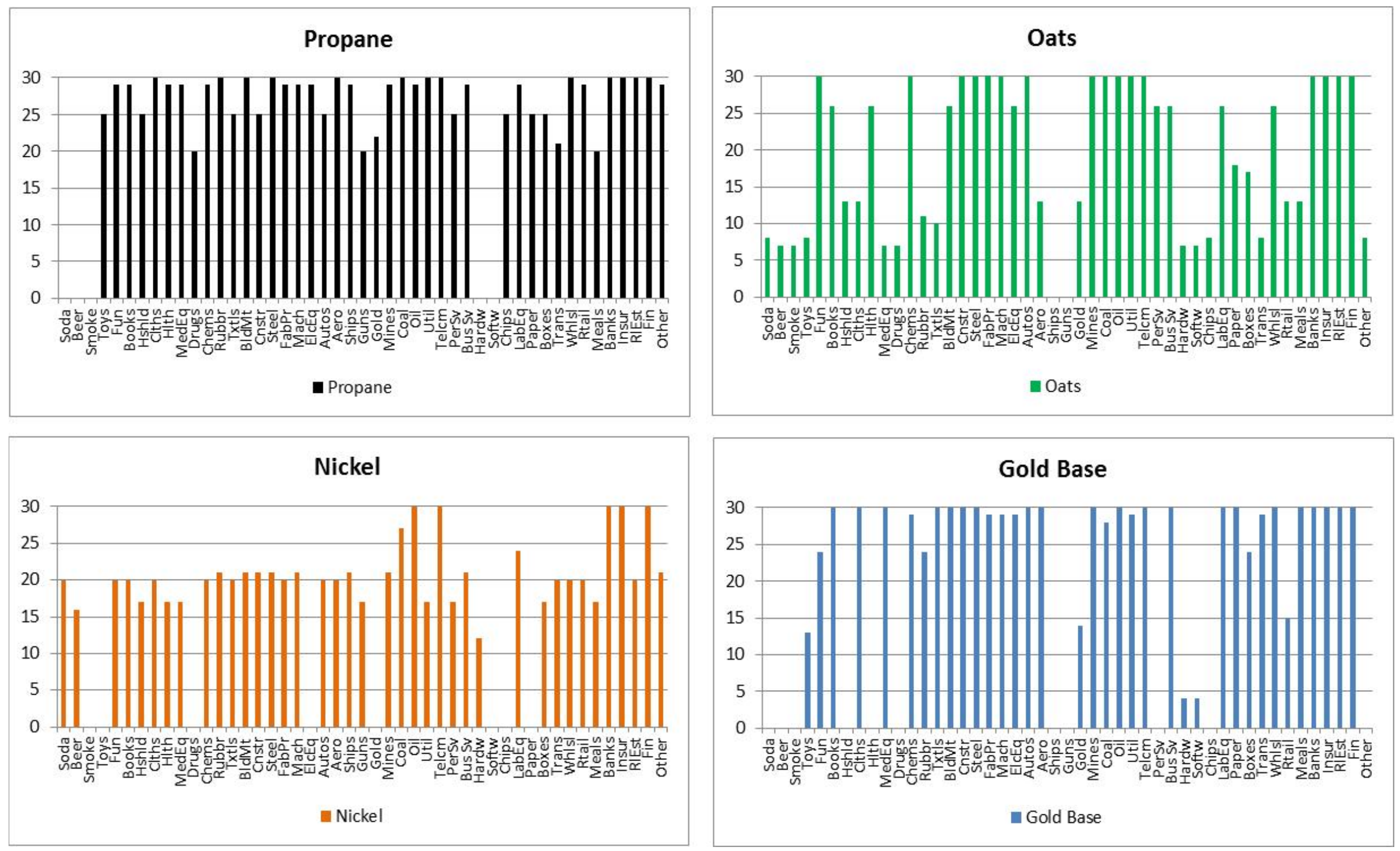

Notes: This figure displays results for the Length of Delayed Reaction in days (Y axis) for the Fama-French industry classifications (X-axis). We display results for the commodity with the greatest amount of predictability in each of four commodity categories (energy, grains, industrial metals and precious metals) 
